\title{
Design of Bilingual Course Teaching of Database Principles
}

\author{
Jun Rao \\ Tianjin University of Finance and Economics, China \\ rjnew@sina.com
}

\begin{abstract}
The paper first introduces the necessity of bilingual teaching of database principle, analysis of some difficulties and problems faced in bilingual teaching, teaching content and teaching methods used are bilingual teaching in the curriculum implementation process. Then we discusses the design of curriculum architecture of database principles. This part includes curriculum objectives, selection of textbook. Moreover, we present the methods of teaching, such as bilingual explains for concepts, discussion in class and experimental practice. Finally, to test the level of study roundly, we adopt server assessment methods that include class performance, experimental reports and final examination.
\end{abstract}

Keywords-Database Principles; Bilingual Course; Curriculum Design; Experimental Practice

\section{INTRODUCTION}

Computer science is a new discipline born in the information age, and its occurrence and development are in some English speaking countries. In the United States, for example, the country's information technology is the first in the world, from industry to academia has focused on a large number of industry elite [1].

The dominance of the United States as the representative of the English speaking countries in the IT industry, determines the disciplines of information technology, many advanced materials are written in English, in order to grasp the advanced theory and technology, it is imperative to improve the professional English level, and improve the professional English level is the most natural, the most direct way of Implementation Bilingual Teaching in specialized courses [2-3]

This course is one of the compulsory core courses for all major of computer science. This course starts from the basic concept of database system and involves the basic theory of relational data model, standardized design and entity-contact model. The main contents of this course include: Database system structure, the characteristics of relational database, the mathematical method and mechanism of data manipulation language, the principle and mechanism of database security, integrity, data access and control, the database design method and its application in practical problems [4-6.]

The database course itself is suitable for bilingual teaching. In the course of database principle as an example, the course as a compulsory course for the major of computer science and technology, its characteristics are many concepts, terminology, theory of database query language SQL and English is similar to that of the entire course of moderate difficulty, these characteristics determine the implementation of bilingual teaching in the course of database principle is feasible [7-9].

\section{CURRICUlum DeSIGN}

\section{A. Curriculum objectives}

By means of classroom teaching, group discussion and computer experiment operation, the course aims to enable students to master theoretical knowledge, have knowledge application ability and enhance practical ability. By learning this course, students are familiar with the database system, the related basic knowledge, basic concepts and basic theory; design of data, attribute, tuple, transaction, and constraints and other basic concepts, relational database system and method of systematic understanding; master the definition and operation method of data in database management system.

Moreover, student learn from the design method of conceptual model to relational data model, the preliminary ability to analyze user data demand, the design and implementation of network database system briefly.

\section{B. Selection of Textbooks}

At present, the development and publication of bilingual textbooks lags behind the practice of bilingual teaching. The lack of suitable teaching materials has become an important factor in bilingual teaching. In this regard, a common way is to adopt the original copy of teaching materials, some of the teaching materials are written by senior scholars in the relevant areas of English speaking countries, whether the purity of the language or the professionalism of the content are impeccable.

English copy database course selection of foreign materials of the latest version, A First Course in Database Systems, Third Edition. The book is easy to understand, application oriented, knowledge database system is very suitable for entry learning, at the same time, translation of the book version of database system tutorial, Second Edition. This book had been published by the China machinery press, and students can be used as reference in the study. The content arrangement is also close to the syllabus, especially before each chapter. After the summary and word review, it is suitable for students to study under the lesson. 
Secondly, Chinese textbook we have selected is published by Renmin University of China watermarking, edited by Professor Wang Shan in the "Introduction to database systems", the book is China's first system to clarify the database principle and the techniques and methods of university undergraduate teaching, rich content and advanced the concept of narrative structure is complete, accurate, concise, editing quality is very high, at the same time as technology the progress of constantly updated, choose the book for the basic concept of database system for students to understand. The main content of bilingual course is shown as Table I.

TABLE I. MAIN CONTENT AND HOUR ARRANGEMENT OF TEXTBOOK

\begin{tabular}{|c|c|c|}
\hline Chapter & Main Content & Hours \\
\hline 1 The Worlds of Database Systems & $\begin{array}{l}\text { The Evolution of Database Systems and Overview of a Database } \\
\text { Management System }\end{array}$ & 2 \\
\hline 2 The Relational Model of Data & $\begin{array}{l}\text { Overview of Data Models, Basics of the Relational Model and } \\
\text { Defining a Relation Schema in SQL }\end{array}$ & 6 \\
\hline $\begin{array}{l}3 \text { Design Theory for Relational } \\
\text { Databases }\end{array}$ & $\begin{array}{l}\text { Functional Dependencies and rules, Design of Relational Database } \\
\text { Schemas and Third Normal Form }\end{array}$ & 6 \\
\hline 4 High-Level Database Models & $\begin{array}{l}\text { The Entity/Relationship Model, Design Principles, Constraints in } \\
\text { the E/R Model and Evolution From E/R Diagrams to Relational } \\
\text { Designs. }\end{array}$ & 8 \\
\hline $\begin{array}{l}5 \text { Algebraic and Logical Query } \\
\text { Languages }\end{array}$ & $\begin{array}{l}\text { Relational Operations and Operators of Relational Algebra, A } \\
\text { Logic for Relations }\end{array}$ & 4 \\
\hline 6 The Database Language SQL & $\begin{array}{l}\text { Queries in SQL, Sub-queries, Full-Relation Operations, Database } \\
\text { Modifications and Transactions in SQL }\end{array}$ & 8 \\
\hline 7 Constraints and Triggers & $\begin{array}{l}\text { Keys, Constraints on Attributes and Tuples, Modification of } \\
\text { Constraints, Assertions and Triggers }\end{array}$ & 4 \\
\hline 8 Views and Indexes & $\begin{array}{l}\text { Creating and Modifying Views, Indexes in SQL, Selection of } \\
\text { Indexes and Materialized Views }\end{array}$ & 4 \\
\hline 9 SQL in a Server Environment & The Three-Tier Architecture and Stored Procedures & 4 \\
\hline $\begin{array}{l}10 \text { Advanced Topics in Relational } \\
\text { Databases }\end{array}$ & Security and User Authorization in SQL and Recursion in SQL & 2 \\
\hline
\end{tabular}

\section{TEACHING METHODS}

\section{A. Classroom teaching and discussion}

\section{1) Using multimedia teaching.}

Due to the wide content and large amount of information in the original edition, in order not to affect the teaching progress, multimedia teaching must be used, not only vivid and intuitive, but also can increase the teaching capacity and improve the quality of teaching. Moreover, the principle of database system is a highly professional discipline, a lot of content on the teacher and the blackboard is difficult to explain clearly, with vivid image and multimedia courseware as an auxiliary tool, and database management software demo, it easier for students to understand. Another outstanding advantage of making electronic teaching plans is that students can download lesson plans at any time. They don't have to be busy taking notes while they are in class, and they can concentrate on listening. In order to let students better digest and understand what they have learned in class, courseware is put on the website for preview and review. 
2) Alternating interpretation of English and Chinese.

Bilingual teaching does not mean the balanced use of two languages in class. The proportion of English and Chinese in class should be determined according to the specific circumstances. Generally speaking, we advocate writing on the blackboard in English, including professional terms and key sentences. The contents which are easy to understand are taught in English, and the emphasis and difficulty of the theory are strong and difficult to understand. The explanation in English is not easy to understand, and the Chinese explanation is used.

After completing each chapter, the teacher summarizes in English, and then gradually makes a summary of the students. Encouraging students to ask questions in English, when they are unable to express themselves, are also allowed to express in Chinese, and then retell them in English by teachers or other students. Encourage students to answer assignments and exam questions in English.
3) Setting up a discussion section.

Oral discussion and even debate can not only enliven the classroom atmosphere, deepen the students' impression, but more importantly, the debate reflects the active and collision of thinking. Because there is no diligent thinking, independent thinking habits, will not find problems, there will not be disputes. And through argument and excuse, it can make the thinking process explicit, let more people participate in the process of thinking, encourage each other, influence, form brainstorming, and finally find the correct answer to the problem. This process is also the process of training and training innovative thinking. At the same time, taking into account the characteristics of bilingual teaching, encourage students to answer in English. In this way, through the debate between students and even between teachers and students, not only exercise the students' oral expression ability, including language ability, but also cultivate and train the students' innovative thinking ability.

TABLE II.

MAIN CONTENT AND HOUR ARRANGEMENT OF EXPERIMENTS

Experiment

Main Content

Hours

\begin{tabular}{|c|c|c|}
\hline \multirow{3}{*}{$\begin{array}{l}\text { 1. Creating Database And Data } \\
\text { Table }\end{array}$} & 1.1 SQL Server Graphical Management Interface & \multirow{4}{*}{2} \\
\hline & 1.2 Database Creation & \\
\hline & 1.3 Database Maintenance & \\
\hline \multirow{5}{*}{ 2. Single Table Query } & 1.4 Definition And Modification Of Data Table & \\
\hline & 2.1 Target Column Selection, Calculation And Other Operations & \multirow{4}{*}{6} \\
\hline & 2.2 Meet The Conditions Of The Query Tuple & \\
\hline & 2.3 To Sort The Query Results Output & \\
\hline & 2.4 Aggregation Functions And Grouping Query & \\
\hline \multirow{4}{*}{$\begin{array}{c}\text { 3. Join Queries And Nested } \\
\text { Queries }\end{array}$} & 3.1 Query Usage & \multirow{4}{*}{6} \\
\hline & 3.2 Nested Query Usage & \\
\hline & 3.3 Related Sub Queries & \\
\hline & 3.4 Connection Query And Nested Query Equivalence From & \\
\hline \multirow{4}{*}{$\begin{array}{l}\text { 4. Data Update And View } \\
\text { Operation }\end{array}$} & 4.1 Data Insert & \multirow{4}{*}{8} \\
\hline & 4.2 Data Modification & \\
\hline & 4.3 Delete Data & \\
\hline & 4.4 The Basic Operation Of View & \\
\hline \multirow{4}{*}{$\begin{array}{l}\text { 5. Database Design And } \\
\text { Implementation }\end{array}$} & 5.1 Database System Needs Analysis And Functional Design & \multirow{4}{*}{4} \\
\hline & 5.2 Data Flow Diagram, E-R Drawing & \\
\hline & 5.3 The Integration From The Local View To The Whole View & \\
\hline & 5.4 Database System Function Realization & \\
\hline
\end{tabular}




\section{B. Using MOOC to complete self-study outside class}

With the advent of the Internet age, many top universities in the United States, such as Harvard University, Yale University, MIT, open online courses, providing a large number of teaching resources. Carrying out bilingual teaching is helpful to draw lessons from foreign teaching mode, and use the excellent teaching resources abroad to improve the teaching quality and shorten the gap.

\section{Experimental Practice}

In the curriculum design of the database, all software labs use English software, such as English version of Windows, SQL Server and Visual Studio and other related software; instructions for use is English version, software use a large number of application examples, practical, students can understand. When students complete the experimental practice, they can make a concentrated summary of the English and database knowledge learned in this semester.

The main content and hour arrangement of experiments is shown in Table II.

\section{ASSESSMENT METHOD}

In addition to assessment methods to examine students' professional knowledge, but also the evaluation of the students' English level, the approach is the introduction of an English test. Secondly a certain number of text translation should be arranged in class. Finally it is required to submit a summary and report by English.

The scoring method is more open, not only to the final volume score, but also to the usual assignments, classroom lectures and performance, and final course design, etc., and comprehensively evaluate students' academic achievement. For the $10 \%$ class performance grades, grade of test report accounted for $20 \%$, accounting for $70 \%$ of the total mark of the final exam. The classroom performance mainly inspects the students' usual speech, participation in class discussion and practice activity, and encourages students to participate actively.

At the part of the experimental reports, teacher will introduce the experimental requirements and the specific experimental content before each experiment, and the students need to complete the experiment report, and write out the experience and record the difficulties encountered in the process of experiment and the solutions. The final examination is required to be completed within the prescribed time in the form of closed examination.
The final examination papers are all English questions and require students to answer them in English. Questions include: Radio questions, fill in the blanks, simple answer, comprehensive questions, etc. Focus on the basic concepts and basic knowledge of the database; the understanding of the basic theory; the ability to analyze and solve the problem comprehensively using knowledge.

\section{SUMMARY}

The bilingual teaching course construction of database principle plays an important role in the construction of computer major. The author of the bilingual textbook selection, teaching methods and assessment methods to do some research on the improvement of local education, cultivate has certain reference significance of internationalization of computer talents needs of society and times. The teaching practice shows that bilingual teaching can improve the teaching effect to a certain extent, but it is still in its infancy and needs further exploration.

\section{REFERENCES}

[1] Gu Ping, Li Tao, Qin Liangxi. Research on Bilingual Teaching of database course and practice [[J]. Journal of Guangxi University: Philosophy and Social Sciences Edition, 2006 (10): 165-166.

[2] Yue Kun, Kong Bing, the exploration and practice of bilingual teaching of database design and application, $[[\mathrm{J}]$. higher education of science, 2006 (5): 138-140.

[3] Hu Bin, Huang Wei, Huang Tianqiang. Research and exploration of bilingual teaching in database course $[\mathrm{J}]$. Journal of Guangxi University For Nationalities: Philosophy and Social Sciences Edition, 2007, 29 (12) 190-191.

[4] Xu Xiaoling. Bilingual teaching exploration of database principles [J]. Information technology education in China, 2013, No.167 (3): 125-127.

[5] Li Fengying, Hou Jie, Wei Qian. Research on Bilingual Teaching of database system principle [J]. Computer education, 2010, No.120 (12): 84-86.

[6] Huang Jing. The practice of bilingual teaching in the course of database principle _ exploration [J]. Computer education, 2008, No.72 (12): 4 , 39-40

[7] Ma Sha, Li Kangshun. Exploration and practice of bilingual teaching of database system [J]. Computer education, 2011, No.134 (2): 58-61, 81.

[8] Liu Jingze, Zhao Xiuying, Zhang Yan. Research summary and development prospect of bilingual teaching in Chinese universities [J] Journal of Hebei Normal University (EDUCATIONAL SCIENCE EDITION), 2006, volume deficiency (5): 115-118

[9] Xue Bing, Chen Qiuhong, Journal of practice and reform measures of [J] Zhang Kai of Henan University Of Urban Construction. bilingual teaching database principle 2010, v.19; No.80 (3): 64-65, 78 